\title{
Transferred plasma jet as a tool to improve the wettability of inner surfaces of polymer tubes
}

\author{
Vadym Prysiazhnyi, Vinicius F. B. Saturnino \& Konstantin G. Kostov
}

To cite this article: Vadym Prysiazhnyi, Vinicius F. B. Saturnino \& Konstantin G. Kostov (2017) Transferred plasma jet as a tool to improve the wettability of inner surfaces of polymer tubes, International Journal of Polymer Analysis and Characterization, 22:3, 215-221, DOI: 10.1080/1023666X.2016.1277053

To link to this article: https://doi.org/10.1080/1023666X.2016.1277053

Accepted author version posted online: 01 Jan 2017.

Published online: 25 Jan 2017.

Submit your article to this journal $\widetilde{C}$

山ll Article views: 58

View Crossmark data ¿ 


\title{
Transferred plasma jet as a tool to improve the wettability of inner surfaces of polymer tubes
}

\author{
Vadym Prysiazhnyi, Vinicius F. B. Saturnino, and Konstantin G. Kostov \\ Faculty of Engineering, Sao Paulo State University, Guaratingueta, Sao Paulo, Brazil
}

\begin{abstract}
The wettability of the inner surfaces of vinyl, polyurethane, and silicone tubes was modified using an atmospheric pressure plasma jet operated in argon. A specific plasma jet configuration, transferred plasma jet, developed at Sao Paulo State University was utilized. It has been shown that it is possible to homogeneously alter the inner wall wettability of 1-m-long tubes, while providing safe plasma source usage for the operator. The water contact angle for three tube materials, i.e., vinyl, polyurethane, and silicone, changed from $98^{\circ}, 86^{\circ}$, and $109^{\circ}$ to $55^{\circ}, 45^{\circ}$, and $40^{\circ}$, respectively.
\end{abstract}

\section{ARTICLE HISTORY}

Submitted 13 December 2016

Accepted 23 December 2016

\section{KEYWORDS}

Plasma jet; polymer tube; polyurethane; silicone; tube inner surface treatments; vinyl

\section{Introduction}

In the last 20 years, atmospheric pressure plasmas have passed through a phase of extensive growth. A wide variety of control parameters (plasma source geometry, composition of working gases or surrounding environment, power supplies) allowed obtaining promising results for the use of plasma as a tool for surface modifications in nearly any application area.

The plasma modification of inner surface of polymer tubes, as surface activation or deposition of functional coatings, has been studied for more than few decades. Number of papers reported the use of low-pressure plasma for inner surface modifications ${ }^{[1]}$ or deposition of functional coatings. ${ }^{[2-4]}$ Recently, several works showed that atmospheric plasmas can be also used for this purpose. For example, decontamination of PTFE located on the inner tube surface was reported, ${ }^{[5]}$ where the treated tube was used as a barrier dielectric in cylindrical DBD (one electrode was inserted inside the tube, while other was wired on its outer surface). Disadvantages of such system are rather complicated procedure to place electrode on the treated tube and exposure of operator to high voltage. Another alternative method was presented by Chen et al. ${ }^{[6]}$ They use an Ar plasma jet in direct contact with the tube to be treated. Plasma ignited inside the tube in the presence of He flow. Authors showed that the plasma inside the tube functionalize the inner surface and increase surface wettability, but the use of He for such procedure makes the cost of treatment high.

The possibility to control surface functionalities of polymers by both low-pressure ${ }^{[7]}$ and atmospheric pressure reactors ${ }^{[8]}$ were presented in details, especially with respect to bio-applications. Cho et al. ${ }^{[9]}$ demonstrate the importance of surface functionalities on smooth muscle cell adhesion in the PTFE tubes. By adjusting the treatment conditions (varying roughness or depositing thin coating with certain functionalities), authors demonstrate that cell adhesion can be controlled. Lauer et al. ${ }^{[10]}$ showed that altering the surface wettability allows not only to directly affect the bio-applicability of polymer surface but also to create favorable conditions for other techniques (in their case, conventional deposition of PEO-like surfactant) that reduced the adhesion of blood platelets on polyethylene tubing. De et al. ${ }^{[11]}$ show correlation between the endothelial cell adhesion and surface wettability of 
polyurethane. Using He plasma treatment, they were able to achieve four times higher amount of cell cultures and increase in cell adhesion (from 29 to $71 \%$ using standard laminar flow tests). The relation between surface wettability and protein adhesion on LDPE was investigated by Xu et al. ${ }^{[12]}$ It seems that a contact angle value around $60^{\circ}$ is particularly important for several bacteria type, when adhesion force value changes. Based on all mentioned works, it is apparent that surface wettability plays an important role for bio-applications.

We have developed a plasma jet transferred through a long plastic tube that is suitable for easy and safe treatment of plastic tubes inner surfaces. In this work, a study of inner surface wettability change of three polymer tubes (vinyl, polyurethane, and silicone) after APPJ treatment is presented. The results showed that our configuration allows decreasing the water contact angles to reasonably low values (less than 60degrees) while providing safe operation (low risk of electrical shock to operator).

\section{Experimental}

Plasma jet was generated at the end of $110-\mathrm{cm}$ commercial polyurethane nasogastric feeding tube (CPL Medical's, Sao Paulo, Brazil) with $2 \mathrm{~mm}$ inner diameter and $3 \mathrm{~mm}$ outer diameter. The jet was ignited at the end of the $0.5-\mathrm{mm}$ steel wire placed inside the tube (it serves as a guide for the feeding tube). The other end of wire served as a second electrode in a closed DBD chamber made of polyoxymethylene polymer. ${ }^{[13]}$ High voltage was applied to the primary DBD discharge, therefore, there was no danger of electric shock using the remote plasma jet. A schema of the experimental setup is presented in Figure 1. High voltage was supplied by a Minipuls 4 AC generator (GBS Elektronik $\mathrm{GmbH}$, Germany) that produced a modulated HV signal. The signal shape is presented in Figure 2, and it has a consecutive HV oscillation with $1.5 \mathrm{~ms}$ of voltage-off period between them. Each group contains 10 cycles of a sine-like wave of $31 \mathrm{kHz}$ frequency. Applied voltage amplitude varied from 11 to $15 \mathrm{kV}$, but most of the experiments were performed at $14 \mathrm{kVp}-\mathrm{p}$. Ar gas flow varied from 0.2 to $2 \mathrm{~L} / \mathrm{min}$.

The treatment of plastic tube inner surface was done by inserting the nasogastric tube with jet nozzle inside, while a cylindrical grounded electrode was attached on the outer side of the tube. Grounded electrode was either aluminum tape ( $0.3 \mathrm{~mm}$ thickness), or $0.5-\mathrm{mm}$ copper wire wrapped around the tube in a form of a solenoideither tight or with $7 \mathrm{~mm}$ distance between the loops. The length of the grounded electrode was fixed to $4.5 \mathrm{~cm}$. Treatment of long tubes were performed using tube movement while the nasogastric tube and the grounded electrode were kept static. It is necessary to define two distances (Figure 1) that will be used in this work: (1) the distance between the

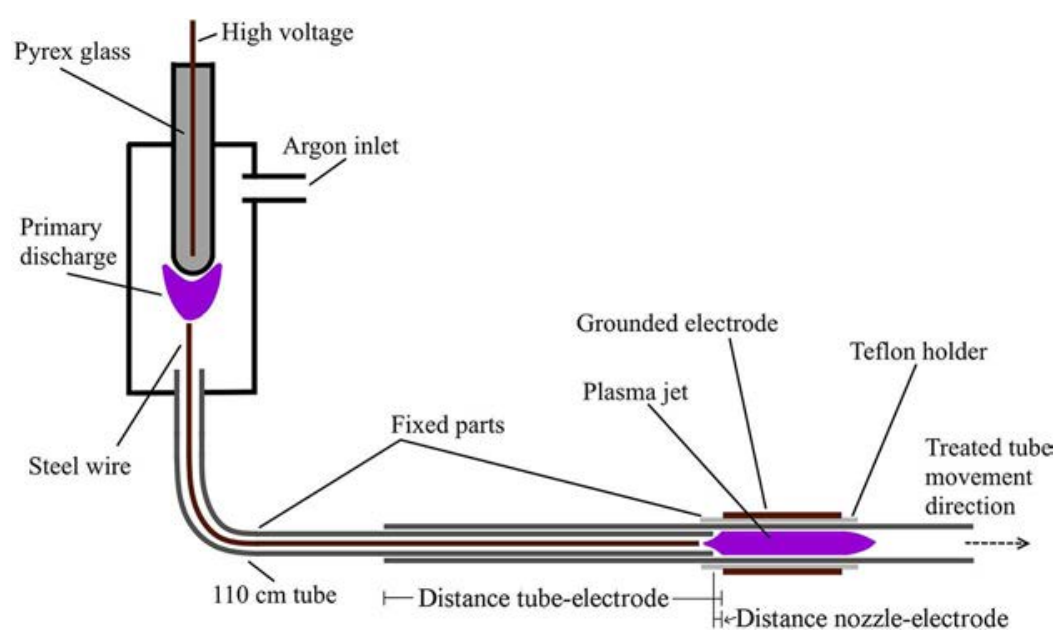

Figure 1. Schema of experimental setup. 




Figure 2. Shape of the voltage signal.

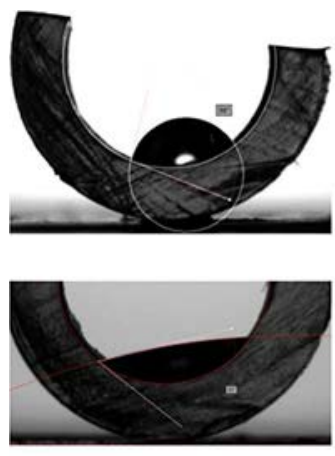

Vinyl, $1.6 \mathrm{~L} / \mathrm{min}, 10 \mathrm{~s}$
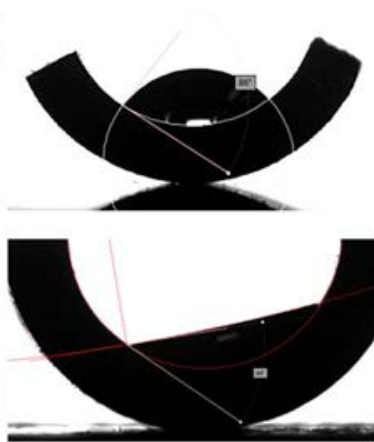

$\mathrm{PU}, 0.8 \mathrm{~L} / \mathrm{min}, 10 \mathrm{~s}$



Silicone, $1.6 \mathrm{~L} / \mathrm{min}, 60 \mathrm{~s}$

Figure 3. Water droplet profiles for untreated (top) and treated (bottom) samples of all three materials.

beginning of the polymer tube and the beginning of the cylindrical grounded electrode (will be referred in the text as distance "tube-electrode") and (2) the distance between the end of the nasogastric tube (or jet nozzle) and the beginning of the cylindrical grounded electrode (will be referred as distance "nozzle-electrode").

Polymer tubes were vinyl (biocompatible) with $4 \mathrm{~mm}$ I.D./6 mm O.D. size, polyurethane (for technical liquids) with $4 \mathrm{~mm}$ I.D./6 mm O.D. size and silicone (for fuels) with $4 \mathrm{~mm}$ I.D./7 mm O.D. size. All tubes were used as received (without pre-cleaning). Electrical characterization of plasma jet was performed by measuring current waveforms (through a $10-\mathrm{Ohm}$ inductance-free resistor connected in series with grounded electrode) and total dissipated power (using Lissajous figure technique explained in detail elsewhere $\left.{ }^{[14]}\right)$. To assess the inner surface wettability, a sessile drop method was utilized on a Ramé-Hart goniometer, model 300. To measure the inner surface wettability, a 3-mm piece of tube was cut and sliced in half. Water drops of $2 \mu \mathrm{l}$ were placed inside each piece of the cut tube, and the formed contact angles were measured several times to ensure homogeneity of the treatment. The value of contact angle was evaluated as the angle between two tangential lines to a circle that fits to the inner tube surface and water drop (example can be seen in Figure 3).

\section{Results and discussion}

An electrical characterization of the plasma jet was performed to find the optimum treatment conditions (stable discharge characteristics independently on position of the treated tube). We varied several parameters: shape of the grounded electrode (it was either solid tape or solenoid-like wired 


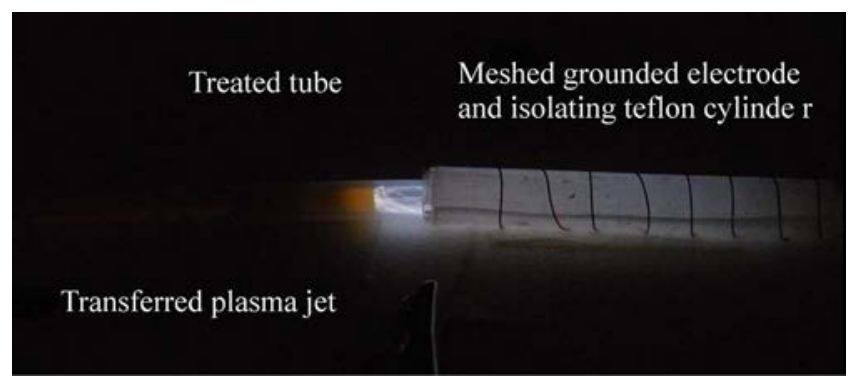

Figure 4. Photo of the transferred plasma jet with solenoidal electrode treating vinyl tube.

electrode wired either tight or not), gas flow, applied voltage, and distance between the end of the plastic tube and the beginning of the grounded electrode. For example, Figure 4 shows solenoid-like wire electrode with $7 \mathrm{~mm}$ spacing with nozzle-electrode distance of $15 \mathrm{~mm}$. Electric current and dissipated power were monitored while varying these parameters.

For typical operation conditions (gas flow from $0.8 \mathrm{~L} / \mathrm{min}$ up to $2 \mathrm{~L} / \mathrm{min}$, voltages higher than $12 \mathrm{kVp}$-p and short nozzle-electrode distance), the current peaks appear during each voltage cycle. However, when Ar gas flow is set to low values (less than $0.4 \mathrm{~L} / \mathrm{min}$ ) or the distance between the jet and the beginning of the grounded electrode is greatly increased or the applied voltage amplitude decreased, it leads to a gradual disappearance of the current peaks from periods with lower amplitude until plasma disappeared completely. Example of this is demonstrated in Figure 5, where a $30-\mathrm{cm}$ vinyl tube was treated with plasma using $15 \mathrm{~mm}$ nozzle-electrode distance. The current peaks occured only in few HV cycles.

It was observed that the dissipated power depends on one more parameter, which is the treated tube length. For the short tubes (less than $10 \mathrm{~cm}$ ), the dissipated power was about $80 \%$ (or less) from the value that was obtained for longer samples $(30 \mathrm{~cm}$ or more). There was a certain decrease in the power when grounded electrode was placed at the tube end. We can attribute these changes to the fact that for shorter tubes, ambient air probably penetrate into the discharge region, thus dumping the dissipated power as gas composition are changed.

Plasma jet operated with tightly wired grounded electrode showed highest dissipated power, which can be attributed to enhanced electric field. For longer tubes, the dissipated power did not depend on the electrode position, while for short tubes, the relative position of the tube (with respect to the beginning of the grounded electrode) was important.

A certain influence of the treated tube material on the discharge operation was also observed. For example, for vinyl the discharge disappeared completely at about nozzle-electrode distance of $68 \mathrm{~mm}$,

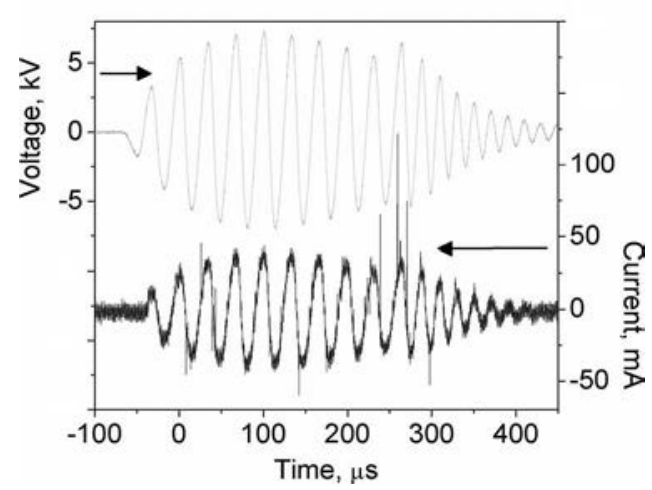

Figure 5. Current and voltage waveform within a single HV group. Voltage $14 \mathrm{kVp}-\mathrm{p}$, jet to grounded electrode distance $15 \mathrm{~mm}$, Ar flow $0.8 \mathrm{~L} / \mathrm{min}, 30-\mathrm{cm}$ vinyl tube are used. 
Table 1. The dependence of treated tube material and geometry on discharge parameters.

\begin{tabular}{lccc}
\hline & $\begin{array}{c}\text { Maximum nozzle-electrode distance } \\
\text { for plasma ignition }(\mathrm{mm})\end{array}$ & $\begin{array}{c}\text { Power at nozzle-electrode } \\
\text { distance 0 mm (W) }\end{array}$ & $\begin{array}{c}\text { Power at nozzle-electrode } \\
\text { distance 15 mm (W) }\end{array}$ \\
\hline Vinyl & 68 & 1.9 & 1.4 \\
Polyurethane & 99 & 3.3 & 3.0 \\
Silicone & 41 & 3.2 & 2.9 \\
\hline
\end{tabular}

Applied voltage $14 \mathrm{kVp}-\mathrm{p}$, gas flow $0.8 \mathrm{~L} / \mathrm{min}$, treated tube length $30 \mathrm{~cm}$, grounded electrode was nontightly wired and positioned at the center of tube.

Table 2. The effect of grounded electrode type and tube length on the dissipated power.

\begin{tabular}{lcccccc}
\hline & Vinyl tube, & Vinyl tube, & PU tube, & PU tube, & Silicone tube, Silicone tube, \\
Power (W) & $8 \mathrm{~cm}$ & $30 \mathrm{~cm}$ & $8 \mathrm{~cm}$ & $30 \mathrm{~cm}$ & $8 \mathrm{~cm}$ & $30 \mathrm{~cm}$ \\
\hline Solid electrode & 2.6 & 2.8 & 3.2 & 4.2 & 3.5 & 4.0 \\
Nontightly wired solenoid (7 mm between loops) & 1.4 & 1.9 & 1.8 & 3.3 & 2.2 & 3.2 \\
Tightly wired solenoid & 2.2 & 2.4 & 3.1 & 5.2 & 3.6 & 4.4 \\
\hline
\end{tabular}

Applied voltage $14 \mathrm{kVp}$-p, gas flow $0.8 \mathrm{~L} / \mathrm{min}$, plasma jet/grounded electrode distance $0 \mathrm{~mm}$, grounded electrode positioned at the center of tube. Experimental error in all cases was $0.1 \mathrm{~W}$.

while for polyurethane, the discharge disappearance was at $99 \mathrm{~mm}$ distance for the same Ar flow of $1 \mathrm{~L} / \mathrm{min}$. Tables 1 and 2 summarize the observed current and power dependences on the distance from the jet to the grounded electrode, and the shape of grounded electrode, respectively. Finally, for the treatments of long tubes, it was decided to operate plasma under $14 \mathrm{kVp}$-p applied voltage with gas flow at least $0.8 \mathrm{~L} / \mathrm{min}$ (for some materials it was necessary to increase the gas flow as the treatment was not homogeneous). Tightly wired grounded electrode was wrapped around the treated tube and the end of the plastic tube was placed on the same position as the beginning of the grounded electrode to obtain maximum discharge power with high uniformity (the dissipated power was almost independent on the position of grounded electrode on the treated tube).

Treatment saturation was studied by varying operational parameters (gas flow, treatment time, and tube length). To ensure homogeneous treatment and do not allow ambient air being mixed in the Ar flow, a tube should have at least $20 \mathrm{~cm}$ length. Therefore, $30-\mathrm{cm}$-long samples were studied. Figure 5 shows the variation of WCA of inner tube surface before and after plasma processing.

Figure 6 shows a gradual decrease in WCA with the increasing treatment time. The values of gas flow were chosen experimentally to achieve homogeneous treatment inside the tubes. As reported in previous works, even a short treatment time is enough to significantly decrease the surface wettability. We decided to perform our final tests using treatment time, which resulted in a contact angle close to saturation value.

Optimum conditions for each material (treatment time and Ar gas flow) were chosen for the final tests, i.e., treatments of inner surface of polymer tubes with $1 \mathrm{~m}$ length. The treatment was done by slowly moving the entire tube while plasma jet and outer grounded electrode were fixed.



Figure 6. Example of the homogeneous WCA decrease depending on the treatment time. 



Figure 7. Distribution of WCA of inner surfaces of 1-m-long (a) vinyl, (b) polyurethane and (c) silicone tubes after plasma modification.

Figure 7(a)-(c) presents the WCA values for treated vinyl, polyurethane, and silicone tubes. As it can be seen, the treatment resulted in a significant increase in the surface wettability for all three materials. The obtained water contact angles $55^{\circ}$ for the vinyl tube, $49^{\circ}$ for the polyurethane tube, and $38^{\circ}$ for the silicone tube are equal or close to the values reported in the literature for these materials. ${ }^{[15-17]}$ The treatment was uniform (within $3^{\circ}$ of uncertainty), except for the end of the tube for polyurethane and silicone. We expect that the reason behind this is admixture of ambient air. As we demonstrated in an earlier work, the length of plastic tube can be extended up to $4 \mathrm{~m}$, which is more than enough for practical implementation of this source. However, the biological experiments will be performed in the nearest future.

\section{Conclusion}

A treatment of inner surface of three polymer tubes (vinyl, polyurethane, and silicone) using a transferred plasma jet was demonstrated. It has been shown that the developed plasma jet 
configuration can be utilized to make a homogeneous treatment of tubes with length up to $1 \mathrm{~m}$. Initially, hydrophobic materials (with water contact angles almost or more than $90^{\circ}$ ) were transformed to hydrophilic ones with WCA less than $55^{\circ}$. The effect of material (plasma plume length and the total dissipated power operated at same conditions) was demonstrated. The proposed geometry of transferred plasma has a high potential of being a safe tool to inner surface tube treatments.

\section{Acknowledgment}

The authors would like to thank Dr. Milton E. Kayama for fruitful discussions and Jose B. Galhardo for technical support.

\section{Funding}

This research was financed by Fundação de Amparo à Pesquisa do Estado de São Paulo (FAPESP 2013/06732-3). Part of the financial assistance was provided by FAPESP project (grant 2015/21989-6).

\section{References}

[1] Jansen, B., H. Steinhauser, and W. Prohazka. 1986. Plasma treatment of the inner surface of polymer tubes for the improvement of their anticoagulant properties. Makromol. Chem. Macromol. Symp. 5:237-244.

[2] Briul, A., L. M. Brenneisen, J. G. A. Terlingen, T. Beugeling, W. G. van Aken, and J. Feijen. 1994. In vitro leukocyte adhesion to modified polyurethane surfaces. II. Effect of wettability. J. Colloid Interface Sci. 165:72-81.

[3] Kuzuya, M., T. Yamashiro, S. Kondo, and M. Tsuiki. 1997. A novel method to introduce durable hydrophilicity onto hydrophobic polymer surface by plasma treatment. Plasma Polymer 2:133-142.

[4] Lackner, J. M., M. Kahn, and W. Waldhauser. 2011. Plasma modification and deposition on inner tube faces by pulsed DC discharges. Vacuum 86:144-150.

[5] Schnabel, U., T. Maucher, J. Kohnlein, W. Volkwein, R. Niquet, I. Trick, M. Stieber, M. Müller, H-P. Werner, J. Ehlbeck, C. Oehr, and K-D. Weltmann. 2012. Multicentre trials for decontamination of fine-lumen PTFE tubes loaded with bacterial endospores by Low and atmospheric pressure. Plasma Process. Polym. 9:37-47.

[6] Chen, F., S. Liu, J. Liu, S. Huang, G. Xia, J. Song, W. Xu, J. Sun, and X. Liu. 2016. Surface modification of tube inner wall by transferred atmospheric pressure plasma. Appl. Surf. Sci. 389:967-976.

[7] Lai, J. Y., Y. Y. Lin, Y. L. Denq, S. S. Shyu, and J. K. Chen. 1996. Surface modification of silicone rubber by gas plasma treatment. J. Adhes. Sci. Technol. 10:231-242.

[8] Kostov, K. G., A. L. R. dos Santos, R. Y. Honda, P. A. P. Nascente, M. E. Kayama, M. A. Algatti, and R. P. Mota. 2010. Treatment of PET and PU polymers by atmospheric pressure plasma generated in dielectric barrier discharge in air. Surf. Coat. Technol. 204:3064-3068.

[9] Cho, Y. K., D. Park, H. Kim, H. Lee, H. Park, H. J. Kim, and D. Jung. 2014. Bioactive surface modifications on inner walls of poly-tetra-fluoro-ethylene tubes using dielectric barrier discharge. Appl. Surf. Sci. 296:79-85.

[10] Lauer, J. L., J. L. Shohet, R. M. Albrecht, C. Pratoomtong, R. Murugesan, S. Esnault, J. S. Malter, U. H. von Andrian, R. D. Bathke, and S. B. Shohet. 2004. Reduced adhesion of human blood platelets to polyethylene tubing by microplasma surface modification. J. Appl. Phys. 96:4539.

[11] De, S., R. Sharma, S. Trigwell, B. Laska, N. Ali, M. K. Mazumder, and J. L. Mehta. 2005. Plasma treatment of polyurethane coating for improving endothelial cell growth and adhesion. J. Biomat. Sci. -Polym. E. 16:973-989.

[12] Xu, L. C., C. A. Siedlecki. 2007. Effects of surface wettability and contact time on protein adhesion to biomaterial surfaces. Biomaterials 28:3273-3283.

[13] Kostov, K. G., M. Machida, V. Prysiazhnyi, and R. Y. Honda. 2015. Transfer of a cold atmospheric pressure plasma jet through a long flexible plastic tube. Plasma Sources Sci. Technol. 24:025038.

[14] Prysiazhnyi, V., A. H. C. Ricci, and K. G. Kostov. 2016. On power measurements of single-electrode low-power Ar plasma jets. Braz. J. Phys. 6:496-502.

[15] Sanchis, M. R., O. Calvo, O. Fenollar, D. Garcia, and R. Balart. 2007. Surface modification of a polyurethane film by low pressure glow discharge oxygen plasma treatment. J. Appl. Polymer Sci. 105:1077-1085.

[16] Wen, X. Q., X. H. Liu, and G. S. Liu. 2010. Improvement in the hydrophilic property of inner surface of polyvinyl chloride tube by DC glow discharge plasma. Vacuum 85:406-410.

[17] Williams, R. L., D. J. Wilson, and N. P. Rhodes. 2004. Stability of plasma-treated silicone rubber and its influence on the interfacial aspects of blood compatibility. Biomaterials 25:4659-4673. 